\title{
When Long Noncoding RNAs Meet Genome Editing in Pluripotent Stem Cells
}

\author{
Fuquan Chen,, ${ }^{1,2}$ Jiaojiao Ji, ${ }^{1,2}$ Jian Shen,, ${ }^{1,2}$ and Xinyi Lu ${ }^{1,2}$ \\ ${ }^{1}$ State Key Laboratory of Medicinal Chemical Biology, Nankai University, Tianjin 300371, China \\ ${ }^{2}$ College of Pharmacy, Nankai University, Tianjin 300350, China \\ Correspondence should be addressed to Xinyi Lu; luxy@nankai.edu.cn
}

Received 30 August 2017; Accepted 25 October 2017; Published 23 November 2017

Academic Editor: Qiang Wu

Copyright (C) 2017 Fuquan Chen et al. This is an open access article distributed under the Creative Commons Attribution License, which permits unrestricted use, distribution, and reproduction in any medium, provided the original work is properly cited.

\begin{abstract}
Most of the human genome can be transcribed into RNAs, but only a minority of these regions produce protein-coding mRNAs whereas the remaining regions are transcribed into noncoding RNAs. Long noncoding RNAs (lncRNAs) were known for their influential regulatory roles in multiple biological processes such as imprinting, dosage compensation, transcriptional regulation, and splicing. The physiological functions of protein-coding genes have been extensively characterized through genome editing in pluripotent stem cells (PSCs) in the past 30 years; however, the study of lncRNAs with genome editing technologies only came into attentions in recent years. Here, we summarize recent advancements in dissecting the roles of lncRNAs with genome editing technologies in PSCs and highlight potential genome editing tools useful for examining the functions of lncRNAs in PSCs.
\end{abstract}

\section{Introduction: Discovery of lncRNAs Expressed in Pluripotent Stem Cells}

Pluripotent stem cells (PSCs) can unlimitedly self-renew and differentiate into specialized cell types of all three germ layers. Therefore, they have been used as an important in vitro model system for studying early development and generating an in vivo genome-edited animal model to analyze the physiological functions of a gene. Furthermore, they were used as a cell source for regenerative medicine to treat macular degeneration recently [1]. The two most frequently used types of PSCs are embryonic stem cells (ESCs), which are derived from inner cell mass of blastocyst, and induced pluripotent stem cells (iPSCs), which are established from somatic cells through reprogramming.

Long noncoding RNAs (lncRNAs) are $>200$ bp long RNA transcripts that lack coding capacity. Most of lncRNAs have evolved rapidly during evolution while a minority of IncRNAs are conserved through species [2]. The rapid evolution of lncRNAs could be partially explained by the presence of transposable elements in lncRNAs, since TEs are major contributors of IncRNA origination and diversification [3]. In the past two decades, expression arrays were first applied to identify novel lncRNAs [4-6]. Later, ENCODE Project Consortium and FANTOM Consortium used a highthroughput sequencing (HTS) method to identify novel transcripts from a genome $[7,8]$. Currently, there are $\sim 87,774$ lncRNAs discovered in mouse cells and $\sim 96,308$ lncRNAs in human cells according to the NONCODE database [9]. Databases of lncRNAs have been established to catalogue novel lncRNAs and their functions (Table 1) [10, 11]. Given the importance of PSCs, further cataloguing of lncRNAs is essential for us to understand the complex regulatory network in PSCs. With the advancement of HTS technologies, ChIP-seq experiments revealed histone modifications as markers of gene transcription units. $\mathrm{H} 3 \mathrm{~K} 4 \mathrm{me} 3$ was found to be a marker of promoter whereas H3K36me3 marked the gene body [12-14]. Therefore, H3K4me3 in combination with H3K36me3 could define the location of a transcribed gene [15]. With the application of histone marks to recognize discrete transcriptional units between protein-coding genes, the first genome-wide discovery of long intergenic noncoding RNAs (lincRNAs) was carried out in four cell types including embryonic stem cells (ESCs) [15]. The same study found that core pluripotency regulators Oct4, Sox2, and Nanog have driven the expression of lincRNAs, which in 


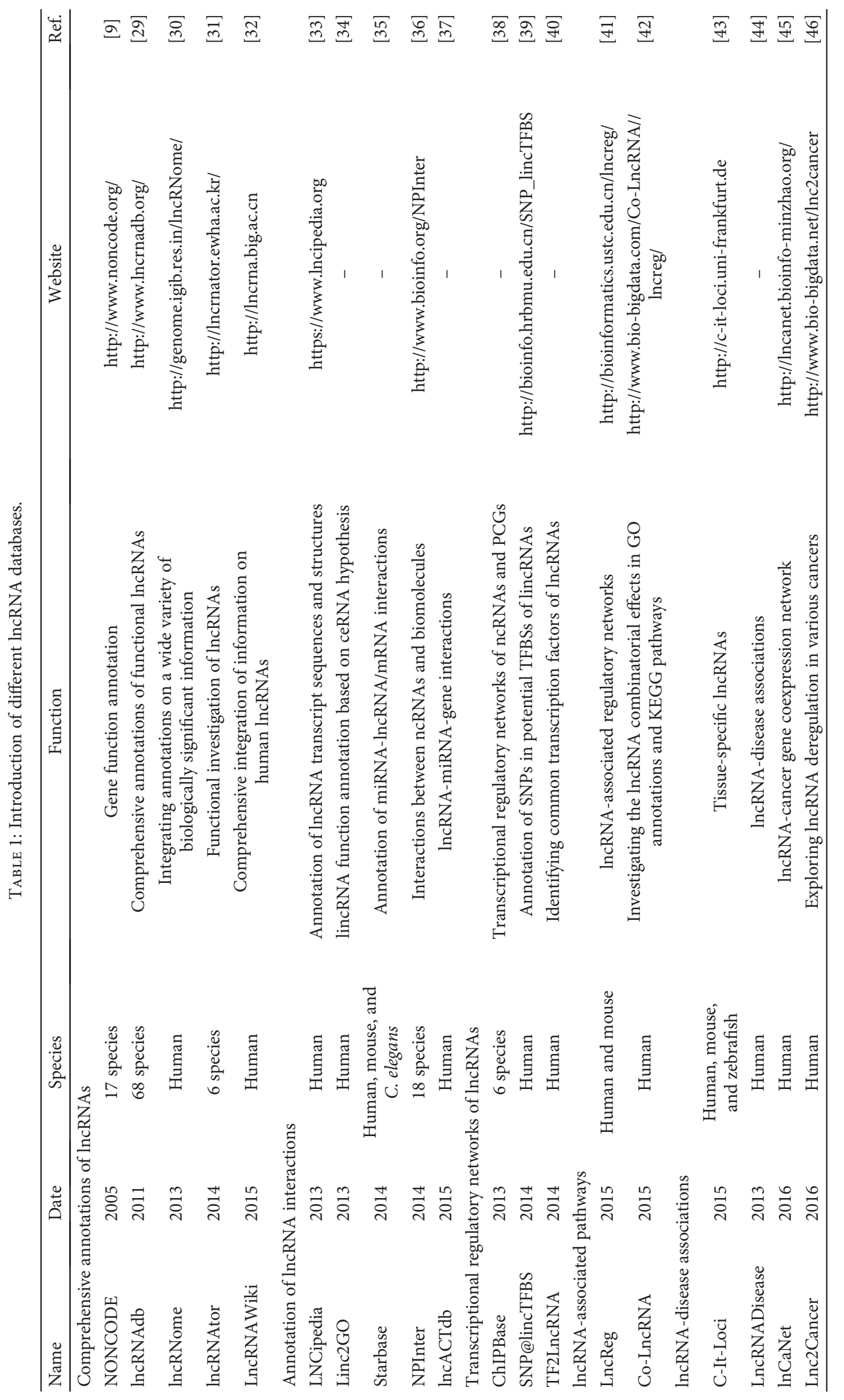


TABLE 2: Classification of lncRNA functional mechanisms and the location of lncRNAs.

\begin{tabular}{lcc}
\hline Mechanism of function & Examples & Ref. \\
\hline Nucleus & & \\
Regulating chromatin-modifying & ANRIL & {$[47]$} \\
complexes & HOTAIR & {$[48]$} \\
& HERVH & {$[17]$} \\
Recruiting transcription factors & PWR1 & {$[49]$} \\
& TUNA & {$[50]$} \\
Chromatin remodeling & HOTTIP & {$[51]$} \\
& SRG1 & {$[52]$} \\
Influencing pre-mRNA splicing & fbp1 ncRNA & {$[53]$} \\
Cytoplasm & MALAT1 & {$[18]$} \\
& EGFR-AS1 & {$[54]$} \\
Regulating mRNA stability & & \\
& Linc-RoR & {$[55]$} \\
& Gadd7 & {$[56]$} \\
Regulating mRNA translation & MEG3 & {$[57]$} \\
& lincRNA-p21 & {$[19]$} \\
Competing for microRNA binding & Antisense & {$[58]$} \\
active small peptides & Uchl1 & {$[59]$} \\
\hline
\end{tabular}

turn regulated the proliferation of ESCs [15]. These findings suggest lincRNAs as critical regulators in ESCs. Most of the discovered lncRNAs are functional [16]. They could participate in the regulation of multiple cellular processes such as transcription, RNA splicing, and translation regulation (Table 2) [17-19]. However, their exact roles in PSCs were mostly uncharacterized. Genome editing methods have been used extensively in probing the functions of proteincoding genes. It is a golden standard to demonstrate the role of a gene. However, the genome editing based on homologous recombination is inefficient, especially in human PSCs [20-23]. The introduction of molecular scissors, like the zinc finger nuclease (ZFN), transcription activator-like effector nuclease (TALEN), and clustered regularly interspaced short palindromic repeat (CRISPR/Cas9) systems, into this field allowed highly efficient genome editing in PSCs and other cell types [24-28]. These recent advances of genome editing technologies permit their more efficient and extensive usage in the analysis of lncRNA functions in PSCs. In this work, we review previous research into classic lncRNAs with genome editing and summarize the recent achievements in studying lncRNAs through novel genome editing technologies in PSCs.

\section{Knockout lncRNAs in PSCs}

The general strategy to study lncRNAs in PSCs is RNA interference (RNAi) mediated by short hairpin RNA (shRNA) or small interference RNA (siRNA). However, RNAi is unsuitable for a loss-of-function study of many lncRNAs. For instance, lncRNAs whose molecular functions are independent of the transcript, that is, the function of these lncRNAs, are from the transcription itself and not from the product of transcription. In addition, some lncRNAs, such as MALAT1, are highly abundant in the nucleus, so RNAi is inefficient in the depletion of these transcripts [62]. To study the physiological relevance of lncRNAs, their knockouts in ESCs or embryos are required to produce homozygous knockout animals. Therefore, it is critical to use genome editing for the loss-of-function study of lncRNAs in these cases to achieve the cleanest depletion of their expression.

2.1. Potential Challenges in the Generation of $\operatorname{lncRNA}$ Knockouts. Molecular scissors have been used to create point mutations in the critical domains of protein-coding genes and in turn induce an early termination of translation to knock out a gene. Different from protein-coding genes, the functional domains of transcripts are still unclear for most lncRNAs; therefore, it is impossible to study lncRNAs by loss-of-function point mutagenesis. Thus, to knock out a lncRNA, complete or partial deletion of the lncRNA gene is required. To avoid indirect influences from lncRNA knockout, we need to manipulate lncRNA genomic loci without affecting the genomic features of other genes. However, under some circumstances, this is difficult to achieve. For lncRNAs that are located at the promoter region of other genes or overlap with exons of protein-coding genes (Figures 1(a) and 1(b)), partial deletion of them by genome editing should only be applied under the circumstances that the expression of other genes remains unaffected. For lncRNAs within the intron of the protein-coding gene, the deletion of lncRNA genes without disturbing the splicing of the intron region is required (Figure $1(\mathrm{c})$ ). The lncRNAs at the intergenic region (Figure $1(\mathrm{~d})$ ), which are distant from other genes, could be easily removed by genome editing technology in a similar manner with protein-coding genes. However, intergenic lncRNA loci which overlap with enhancers (Figure 1(e)), such as enhancer RNAs, are also difficult to study with genome editing, because the deletion of these loci may interfere with the functions of enhancers and affect the expression of distant genes [63]. Therefore, in this section, we will discuss the knockouts of intergenic lncRNAs that do not overlap with enhancers.

2.2. Deletion of the $\operatorname{lncRNA}$ Gene. Whole-gene ablation of lncRNAs is a classic way to learn their functions (Figure 2(a)). Initial work on lncRNA knockouts was done in mouse ESCs but not in human ESCs, because of its early establishment and ease to be manipulated by homologous recombination [64]. ESCs have been used as a model to study imprinting, which occurs during ESC differentiation [65]. One of the first lncRNAs that have been identified and knocked out in mouse ESCs is the lncRNA H19. The homologous recombination-mediated deletion of maternal H19 and its flanking sequences resulted in the expression activation of the imprinting gene Igf2, whereas the deletion of the paternal copy of $H 19$ has no impact on Igf2 expression [66], suggesting $H 19$ as a lncRNA regulating maternal Igf2 


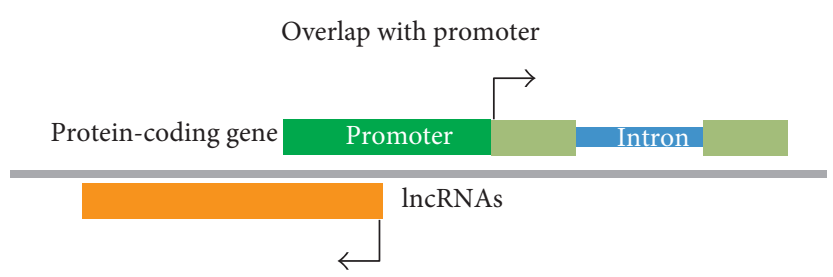

(a)

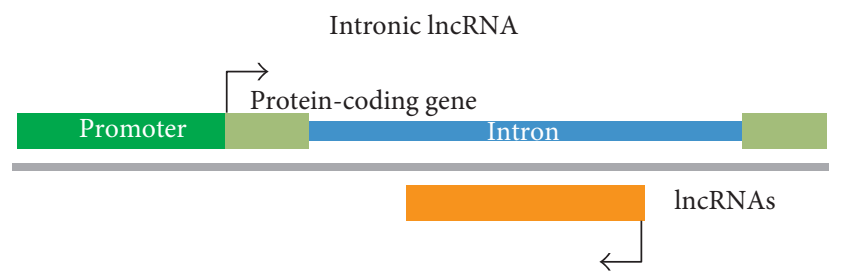

(c)

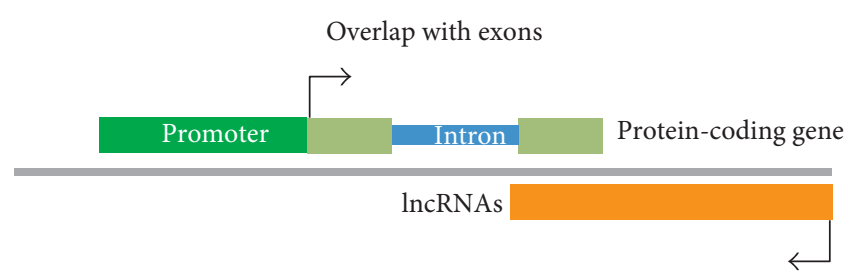

(b)

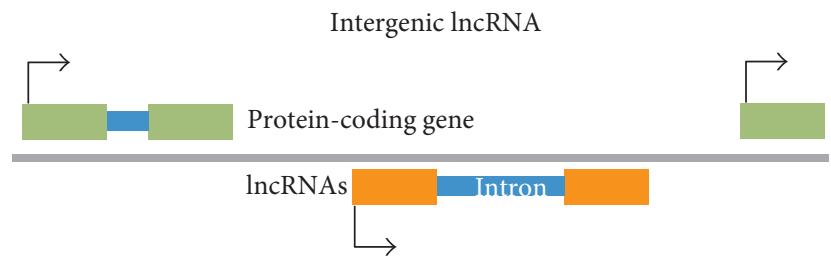

(d)

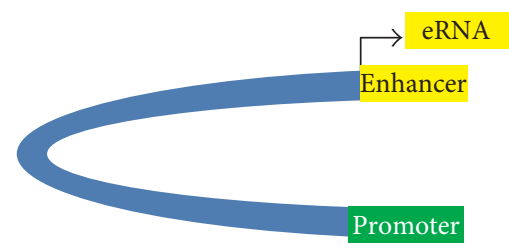

(e)

FIgURE 1: Location of lncRNAs on a human or mouse genome. (a) The lncRNA gene overlaps with the promoter of the protein-coding gene. (b) The lncRNA gene overlaps with exons of the protein-coding gene. (c) The lncRNA gene overlaps with the intron of the proteincoding gene. (d) The lncRNA gene is located between protein-coding genes. (e) lncRNAs, such as enhancer RNA, overlap with the enhancer region.

imprinting. The lncRNA Terc, a 397 bp RNA component of the telomerase complex, is another primary example of lncRNA knockout [67-69]. Ablation of the Terc lncRNA gene resulted in telomere shortening, which subsequently affected chromosome stability and proliferation of mouse ESCs [70, 71]. To improve the gene targeting efficiency, molecular scissors were introduced to engineer lncRNAs in PSCs. ZFNs were used in combination with homologous recombination to delete the highly expressed lncRNA MALAT1 in mouse ESCs. From MALAT1-knockout ESCs, homozygous MALAT1-deleted mice have been generated [62]. TALEN was also used to knock out lncRNAs in zebrafish [72]. With the emergence of the CRISPR/gRNA system, the efficiency of genome editing is higher than before. It was demonstrated that double gRNAs could be applied to efficiently knock out lncRNAs in human cell lines [73]. Using the CRISRP/gRNA system, a full-length lncRNA (HPAT5) was successfully knocked out in human ESCs for the first time [59]. Recently, it is possible to delete the whole H19 transcription unit and imprinting control region (ICR) by the CRISPR/Cas9 system in ESCs [74, 75]. This successfully restored Igf2 expression and faithfully improved the efficiency to generate viable mice from androgenetic zygote and haploid ESCs [74, 75]. These studies demonstrate the complete deletion of IncRNAs through genome editing as an efficient way to discover IncRNA function in ESCs and during differentiation.

Certain lncRNAs are extremely long, so it is difficult to delete a full-length lncRNA gene. In these cases, partial deletion of the lncRNA gene through homologous recombination can be applied for the loss-of-function study (Figure 2(b)). The lncRNA Xist, discovered in the last century, was knocked out in this strategy. Xist, an $\sim 18 \mathrm{~kb}$ lncRNA located on the $\mathrm{X}$ chromosome, functions as a central regulator of gene dosage compensation during ESC differentiation [76, 77]. Homologous recombination strategy was employed to delete part ( $\sim \mathrm{kb})$ of Xist in mouse ESCs [78], but the knockout efficiency is extremely low. More than 2500 clones were screened to identify a single homozygous knockout clone. Through this approach, Xist was found to be required for complete $\mathrm{X}$ chromosome inactivation during ESC differentiation [76, 77]. Heterogeneous knockout of Xist revealed a critical role of Xist for female embryo development [79]. Partial deletion of lncRNAs could also facilitate us to determine the function of RNA domains in lncRNAs. Through homologous recombination-mediated knockout in ESCs, an $890 \mathrm{bp}$ region of the imprinting-related lncRNA KCNQ1OT1 was found to be essential for KCNQ1OT1 to recruit Dnmt1 protein to paternal differentially methylated regions $[80,81]$. With the appearance of genome editing technology, megabase-scale genetic deletions with ZFN [82], TALEN [83, 84], or CRISPR [85] are achievable. The power of CRISPR technology in generating knockout of IncRNAs was demonstrated by the deletion of the lncRNA Rian in ESCs. A pair of sgRNAs in combination with CRISPR could delete $23 \mathrm{~kb}$ of the $57 \mathrm{~kb}$ Rian through zygote injection [86]. In addition, the knockout efficiency reached $33 \%$ if multiple sgRNAs were used [86]. This 


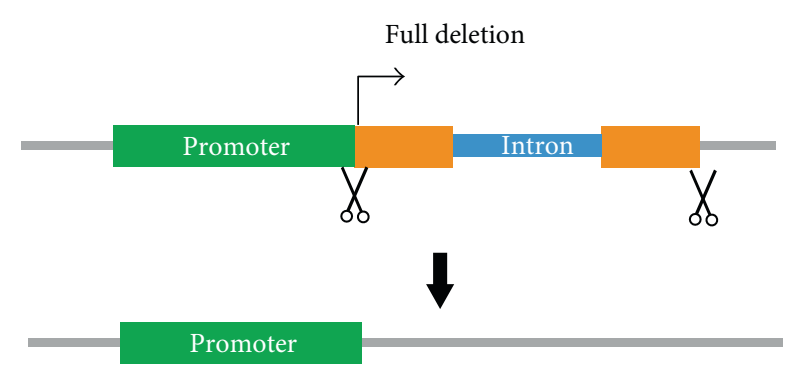

(a)

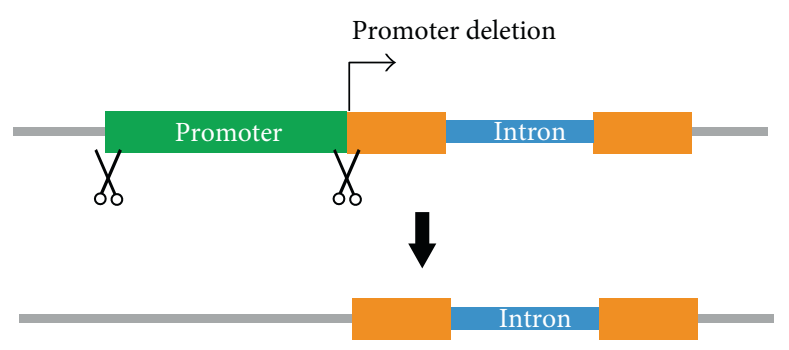

(c)

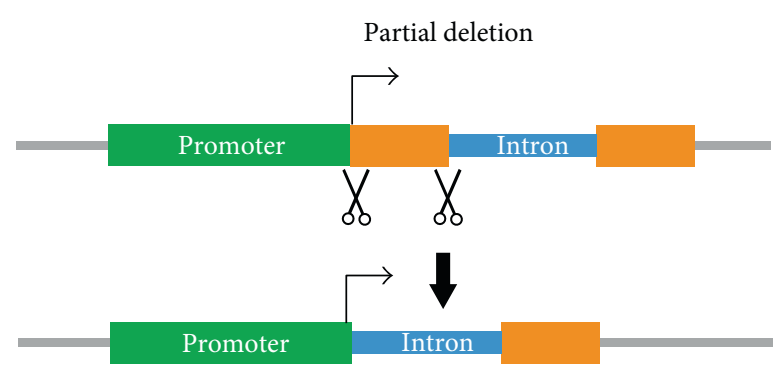

(b)

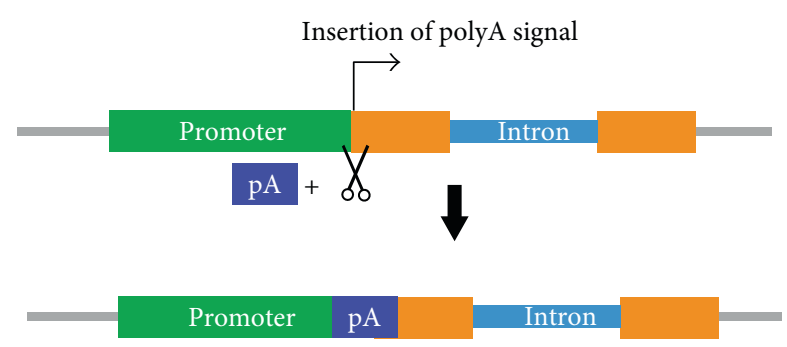

(d)

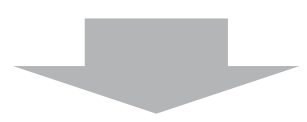

Functions of lncRNAs/transcription locus in ESCs

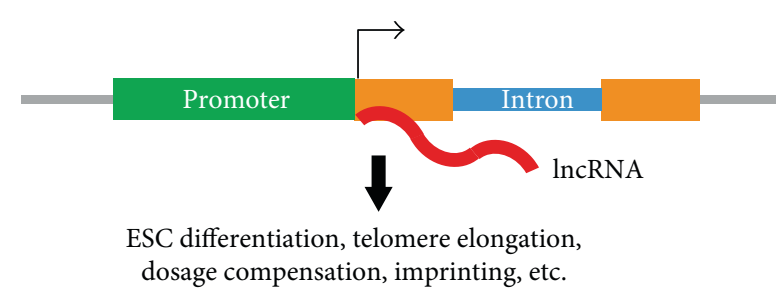

(e)
Generation of an lncRNA in vivo-knockout model

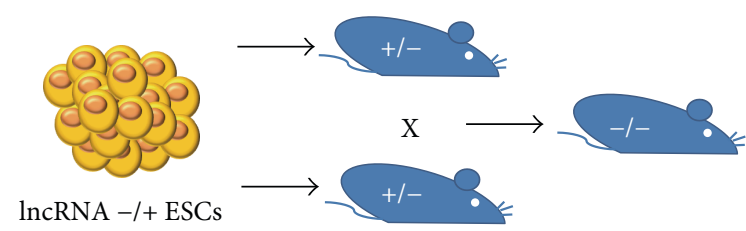

(f)

FIgURE 2: Application of the lncRNA knockout in PSCs. The lncRNA gene knockout can be done through (a) knocking out the whole lncRNA gene from the genome, (b) knocking out part of the lncRNA gene, (c) knocking out the lncRNA promoter region, and (d) inserting poly(A) signal (pA) after the transcription start site. (e) Application of genome editing to study lncRNA functions in ESCs. (f) Application of genome editing in ESC to generate lncRNA-knockout mice.

technology advancement may facilitate us to delete fulllength extremely large lncRNAs in PSCs.

With the discovery of more lncRNAs and further understanding of lncRNAs' functions, the homologous recombination-based knockout of lncRNAs has been more extensively applied to delete lncRNAs in PSCs. In one of the studies, 18 lncRNA genes were knocked out in mouse ESCs to produce IncRNA-knockout mice [87]. The replacement of the lncRNA locus with the lac $Z$ reporter allowed the visualization of the temporal and spatial expression pattern of these lncRNAs in animal models. Another similar study created knockout ESC lines for 20 lncRNAs through gene targeting and used these ESCs to create knockout mice for studying the broad roles of lncRNAs in mice [88]. These IncRNA-knockout mice constitute valuable complements to the resource for studying the physiological roles of lncRNAs.
2.3. Knocking In Polyadenylation Signal. Another strategy to prevent lncRNA transcript production is the knockin of polyadenylation (polyA) signal at the transcription start sites (TSS) (Figure 2(d)). Biallelic insertion of one copy or multiple copies of polyA signal at the beginning of lncRNA gene TSS will cause early termination of transcription and the subsequent failure of IncRNA production [89]. However, for lncRNAs with alternative promoters and transcription TSS, this strategy may not be applicable. This strategy was employed in ESCs to characterize the functions of the lncRNA Fendrr in embryo development [90, 91]. PolyA insertion-mediated Fendrr knockout led to malfunctioned heart and embryonic death by E13.75 in mice, while overexpression of Fendrr through BAC rescued the phenotype. Moreover, this method prevents IncRNA production without disturbing the transcription activity itself. Hence, this approach allows the distinguishment of the function of the 
lncRNA itself from that of its genomic transcription activity. This is exemplified by the case of the imprinting lncRNA Airn. The Airn gene overlaps with Igf $2 r$ promoter regions and is transcribed in the opposite direction of $\operatorname{Igr} 2 r$ [92]. The Airn gene spans more than $100 \mathrm{~kb}$ of the mouse genome and encodes multiple spliced isoforms [92]. Expression of Airn on paternal allele represses the paternal expression of $\operatorname{Ig} 2 \mathrm{f} r \mathrm{Sl} 222 a 3$, and $S l c 22 a 2$ during ESC differentiation $[92,93]$. Surprisingly, truncation of Airn by insertion of polyA signals after TSS did not affect $I g f 2 r$ gene expression [94]. In addition, the overlapped transcription at the Airn promoter region is sufficient to repress $I g f 2 r$ after ESC differentiation [94]. Furthermore, the Airn gene is very large $(>100 \mathrm{~kb})$ and may be difficult to knock out. This study also demonstrates that polyA signal could be a more efficient way to prevent expression of macro lncRNA genes than whole-gene deletion.

2.4. Deletion of the IncRNA Promoter. Promoters of lncRNAs are critical to drive their expression. For intergenic lncRNAs, another strategy to disrupt their expression relied on the removal of the lncRNA promoter by genome editing (Figure 2(c)). With two gRNAs expressed simultaneously, the promoter of lncRNAs could be efficiently deleted to achieve silencing of lncRNA expression [95]. One example is from the classic lncRNA H19, whose knockout allows the derivation of bimaternal mice $[96,97]$. Similar to $H 19$ knockout, deletion of DMRs of lncRNAs H19 and Gtl2 in haploid ESCs by CRISPR represses $H 19$ and Gtl2 expression and allows the generation of semicloned mice from haploid ESCs [16]. These suggest the deletion of the lncRNA promoter region as an efficient approach to silence lncRNA expression in PSCs.

2.5. Combination of Different IncRNA Knockout Methods. The above examples show that a single approach is insufficient to identify the all possible functions of lncRNAs. Multiple genome editing strategies need to be taken in order to discover the functions of lncRNAs and their transcription locus in PSCs. This is well demonstrated in the study of Haunt lncRNAs in ESCs. Yin et al. found that siRNA mediated Haunt lncRNA depletion and deleting a small fraction of the Haunt gene caused a consistent further increment in HOXA expression upon retinoic acid- (RA-) induced ESC differentiation [63]. However, large deletions of the Haunt gene ranging from $7.3 \mathrm{~kb}$ to $58 \mathrm{~kb}$ caused an opposite effect. Disruption of Haunt expression by CRISPR/ Cas9-mediated knockout of $2.3 \mathrm{~kb}$ of the Haunt promoter region or insertion of $4 \times$ polyA signal after transcription start sites also leads to enhanced activation of HoxA cluster genes after ESC differentiation. These observations demonstrate distinct roles of IncRNAs and their corresponding genomic locus in regulating RA-induced HOXA expression. Moreover, this study also implicates that the role of lncRNAs should be examined in different aspects and multiple approaches to reveal the functions of the lncRNA gene locus and its transcripts in PSCs (Figures 2(e) and 2(f)).

\section{IncRNA Reporter Gene in PSCs}

Creation of the lncRNA reporter gene in PSCs allows us to track lncRNA expression in vivo and study the regulation of lncRNAs. In order to create reporter genes of lncRNAs, the differences between lncRNAs and protein-coding genes have to be considered. Unlike protein-coding genes, lncRNAs do not encode proteins. For this reason, it is impossible to make fluorescent fusion proteins through addition of self-cleaving 2A peptide or introduction of internal ribosome entry sites (IRES) to create the lncRNA reporter gene. The addition of protein-coding gene sequences to lncRNAs may interfere the localization and function of lncRNAs, whereas the inclusion of IRES sequence may lead to the recruitment of ribosomes to lncRNAs and conversion of lncRNAs to mRNAs. Therefore, the creation of lncRNA promoterdriven reporters requires genome editing of lncRNAs by knocking in the lncRNA locus or introducing an independently expressed transgene to the genome (Figures 3(a) and $3(\mathrm{~b}))$. However, knocking in the reporter gene to the lncRNA locus will destroy one copy of the lncRNA gene and affect the expression of neighboring genes if the lncRNA acts in cis. Introduction of the lncRNA promoter-driven transgenic reporter may not reflect the true expression pattern of lncRNAs because the usage of enhancers and silencers is different at distinct genomic loci. All these situations need to be considered prior to the establishment of the lncRNA reporter PSC cell line.

The earliest application of the lncRNA reporter in PSCs is to express foreign genes at the lncRNA transcription locus. A primary instance is the Rosa26 locus, which is used to constitutively overexpress genes for $\sim 20$ years. The Rosa26 locus was first discovered in 1991 during gene trapping in ESCs [98]. Later, it was found to encode two nuclear transcripts with no significant open reading frames (ORFs), suggesting them as lncRNAs [99]. Interrupting this locus with the proviral beta geo reporter gene led to ubiquitous expression of beta-galactosidase, suggesting that the Rosa26 locus encodes universally expressed lncRNAs in mice [99]. Since then, the Rosa26 locus has been used as a genetic safe harbor for gene knockin to achieve ubiquitous transgene expression $[100,101]$ (Figure 3(c)). Nowadays, the human Rosa26 locus was also discovered, and numerous genes have been knocked in the Rosa26 locus in ESCs to generate knockin mice and study the function of these genes [101, 102].

lncRNAs are involved in the essential gene regulatory processes during development. The reporter system of lncRNAs is also used to monitor the regulatory status of important biological processes in ESCs and during differentiation. One instance is using the paternal $\mathrm{H} 19$ reporter gene to monitor imprinting status during ESC differentiation. Since H19 expression is essential to maternal imprinting, to avoid the interruption of the $H 19$ gene, the transgene carrying H19 promoter-driven lacZ and PLAP was used as the reporter to reflect the change of imprinting status [103] (Figure 3(d)). Using this reporter system, $1.1 \mathrm{~kb}$ control element was discovered to regulate maternal H19 imprinting [103]. A recent example of the application of the lncRNA reporter is to isolate naive human ESCs. Endogenous 


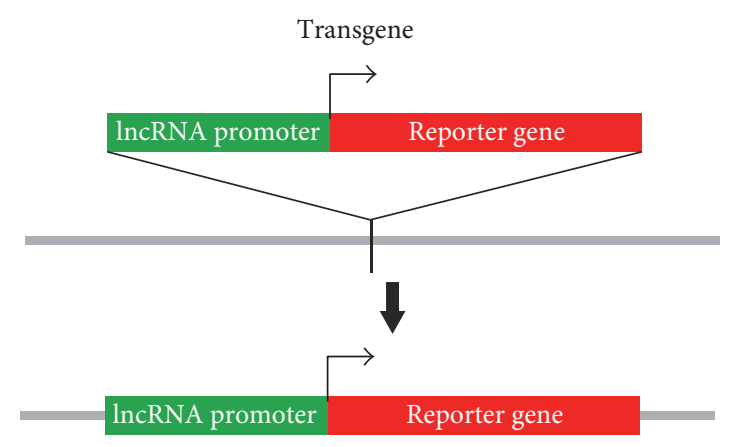

(a)

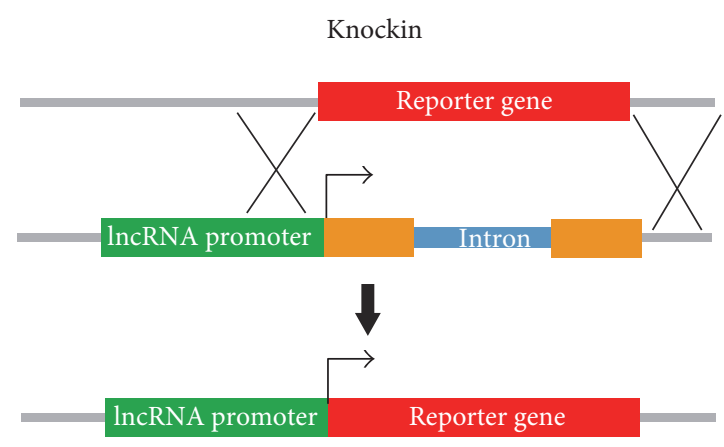

(b)

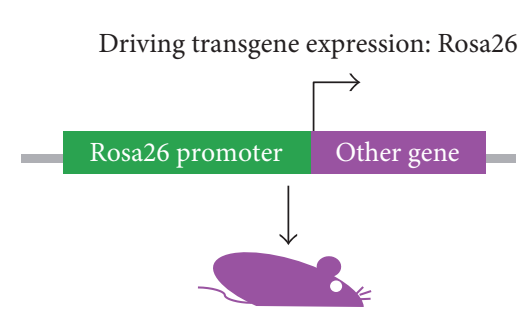

(c)
Monitoring of allele-specific expression: H19

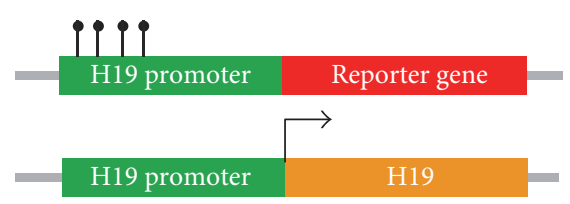

(d)

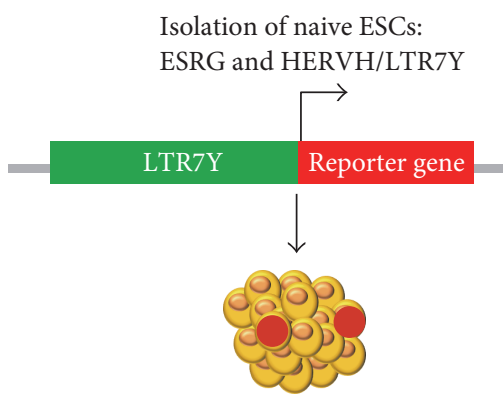

(e)

FIgURE 3: Application of the lncRNA reporter gene in PSCs. Generation of lncRNA reporter genes can be achieved by (a) knocking in the reporter gene to the IncRNA locus and (b) introducing the lncRNA promoter-driven reporter gene. Application of the lncRNA reporter gene in (c) driving the expression of the transgene (such as the Rosa26 locus). (d) Monitoring the allele-specific gene expression. (e) Isolation of naive ESCs (red dot) (such as the ESRG promoter- or LTR7Y-driven transgene).

retrovirus HERVH was discovered as ESC-specific lncRNAs that regulate pluripotency [17]. The HERVH promoter (LTR7Y) is active only in cells from inner cell mass of blastocyst. Thus, the transgenic LTR7Y-driven GFP reporter can be used for the isolation of naive-state human ESCs [104] (Figure 3(e)). It was also found that the reporter gene driven by the promoter of the HERVH-derived IncRNA ESRG marked naive human ESCs [105] (Figure 3(e)). All preceding examples demonstrate the power of IncRNA reporter genes in studying the regulation of lncRNAs and tracking their expression.

\section{Activation and Repression of lncRNAs with Genome Editing Technologies}

Since CRISPR/Cas9-based genome editing technology could efficiently delete large fragments of the genome [86], it has been utilized to perform genome-wide screening of lncRNA functions [106]. Multiple gRNAs were used against one single lncRNA to accomplish efficient ablation of the IncRNA gene expression; therefore, the paired gRNA library could only target a few hundreds of lncRNAs [106]. Using this approach, lncRNAs critical to cancer cell survival have been identified. An alternative approach to modulate lncRNAs with CRISPR-Cas9 is through CRISPR interference (CRISPRi) [107], which is constituted of deactivated Cas9 (dCas9) fused with transcription repressors, such as KRAB. Through the recruitment of dCas9-KRAB to the promoter regions of lncRNAs with multiple gRNAs, the expression of lncRNAs is hindered by the transcription repressors recruited by KRAB protein (Figure 4(a)). CRISPRi was applied to manipulate IncRNA (GAS5, H19, MALAT1, NEAT1, TERC, and XIST) expression in K562 cells [108]. In addition to these lncRNAs, CRISPRi was applied to probe the function of the cheRNA HIDALGO in K562 and H1 human ESCs [109]. This was adapted at a genome-wide scale to perform lncRNA repression screen in various cell types including human induced pluripotent stem cells (iPSCs) [110]. In this way, a number of lncRNAs were discovered as self-renewal regulators of human iPSCs [110]. The efficiency of genome editing is regulated by the epigenetic status of chromatin, such as chromatin conformation. The genome editing efficiency with TALEN and CRISPR is higher for genes at euchromatin than at heterochromatin [111]. This may introduce bias to genome-scale CRISPRmediated screening of gene expression regulators.

Modified CRISPR is applicable not only for depleting gene expression but also for activating gene expression. CRISPR activation (CRISPRa), which utilizes dCas9 fused with multiple copies of strong viral transcription activators such as VP16, activates gene expression by bringing RNA polymerase II to TSS $[107,112]$. This method can be adopted to activate lncRNA expression in ESCs (Figure 4(b)). Traditionally, in terms of the gain-of-function study of lncRNAs, 


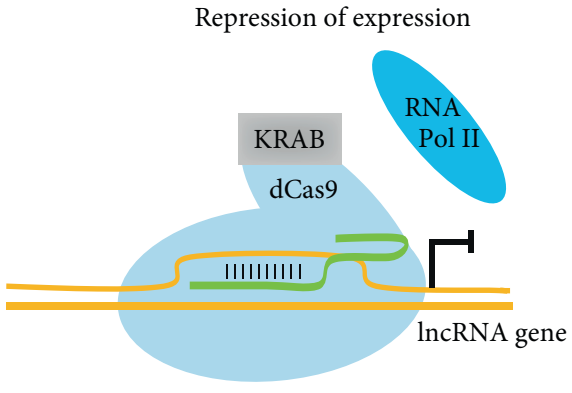

(a)

Recruitment of lncRNA to chromatin

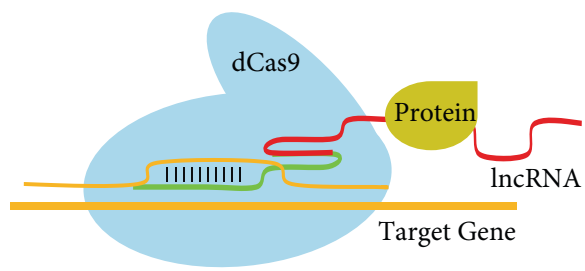

(c)

lncRNA cleavage

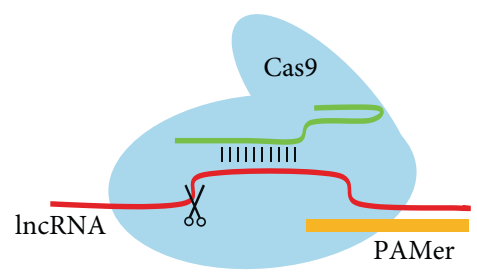

(e)
Activation of expression

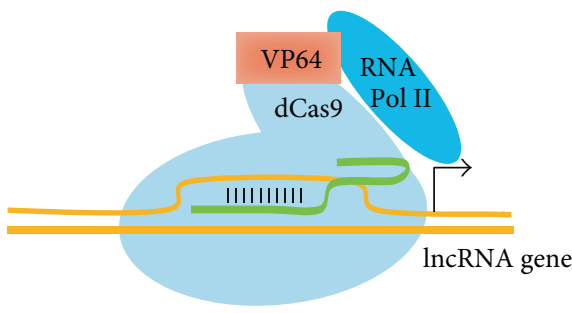

(b)

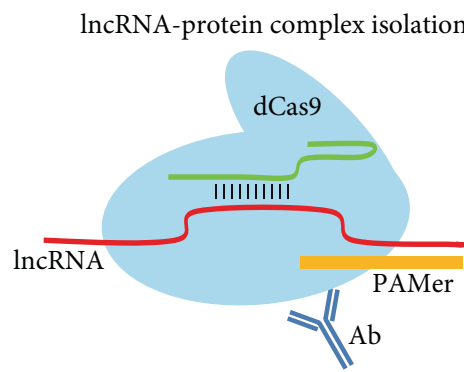

(d)

Monitoring of lncRNA localization

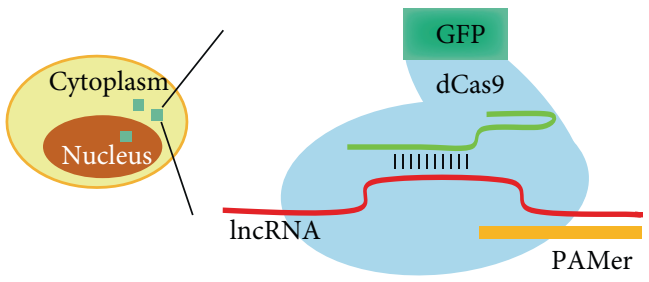

(f)

FIgure 4: Potential applications of the CRISPR/Cas9 system to study lncRNAs in PSCs. Application of CRISPR/Cas9 technology in the (a) repression of lncRNA transcription, (b) activation of lncRNA expression, (c) recruitment of the lncRNA to chromatin, and (d) isolation of the lncRNA-protein complex. (e) Degradation of the lncRNA. (f) Monitoring lncRNA localization. Green strand: gRNA.

plasmid- or transgene-based overexpression of lncRNAs was used. However, different from protein-coding genes, some lncRNAs function during transcription, that is, the production of transcript $[63,94]$. Therefore, exogenous expression of lncRNAs may not reflect the genuine function of lncRNAs. In addition, multiple isoforms are present for some lncRNAs [94]. It is difficult to overexpress all isoforms at the same time. What is more, for some lncRNAs that lack polyA tail or are derived from introns [113], it is important to clone the fraction longer than its expression region. Moreover, for the lncRNA acting in cis, introduction of the lncRNA transgene to other genomic locations for overexpression cannot reflect the true function of lncRNAs. Above difficulties in IncRNA overexpression could be conquered by the usage of CRISPRa to activate the lncRNA. Recently, Joung's group applied CRISPRa in a genome-wide scale to identify lncRNAs that render melanoma cells' drug resistance to vemurafenib [114]. CRISPRa directly activates the expression of endogenous genes from their genomic locus [107], and therefore, it keeps the function of the lncRNA transcriptional region and makes the simultaneous activation of multiple lncRNA isoforms possible. These methods could be applied to PSCs for the gain-of-function study of the lncRNA regulators of pluripotency maintenance.

\section{Other Potential Applications of Genome Editing Tools in Studying lncRNAs in PSCs}

CRISPR/Cas9 is a versatile tool for genome editing and expression regulation. Besides its applications in editing the genetic locus in ESCs, CRISPR/Cas9 can be adopted to investigate other aspects of lncRNA biology in ESCs. A number of nuclear lncRNAs may act by interacting with chromosomes to regulate gene expression $[115,116]$. The inhibition of expression of these lncRNAs by CRISPR/ Cas9-mediated truncation of their promoters will cause downregulation of neighboring genes' expression [109, 117]. To study the role of these lncRNAs, a valuable tool, named CRISPR-Display, was developed to deliver an lncRNAprotein complex to DNA loci [118]. Functional RNA domains can be inserted into gRNAs, allowing the identification of the direct effect of ectopically targeting lncRNAs on chromatin (Figure 4(c)). In addition, this system can be multiplexed to investigate the influences of recruitment of lncRNAs on 
several genomic loci simultaneously. Moreover, it was recently discovered that the CRISPR system could be edited to interact with cellular RNAs. Cas9 directly binds or cuts RNAs in the assistance of DNA PAMmers [119]. This enables the cleavage of RNA or pulldown of mRNA through RNA-RNA hybridization by Cas9-gRNA [119]. It can be used to cleave lncRNAs with Cas9 or pull down lncRNAs with dCas9 in ESCs to analyze the potential interacting proteins of lncRNAs (Figures 4(d) and 4(e)). With this system, dCas9 fused with GFP is targeted to mRNAs to track their localization in live cells with the guidance of sgRNA [120]. This system can also be adopted to study lncRNA position in PSCs and track lncRNA localization in live PSCs (Figure 4(f)).

\section{Conclusions and Perspectives}

In the recent years, thousands of IncRNAs have been identified. Several of them were shown to play important roles in PSCs [116]. However, the advancements in genome editing technologies are just starting to be widely applied in PSCs to study the functions of lncRNAs. Considering the diverse functions of the lncRNA genomic locus and its transcript(s), multiple genome editing approaches should be applied to distinguish the functions of the lncRNA transcript and its gene locus in PSCs. IncRNAs are important biomarkers in embryo development and disease progression. The establishment of the lncRNA reporter in vivo will enable the monitoring of these processes. The development of emerging CRISPR genome editing technologies opens new gates to lncRNA biology in PSCs. Future studies should adopt these novel strategies to probe the functions of lncRNAs in PSCs. These genome editing tools should also be exploited to explore physiological functions of lncRNAs in a systematic scope.

\section{Conflicts of Interest}

The authors declare that there is no conflict of interest present for this study.

\section{Acknowledgments}

This work is supported by grants from the Natural Science Foundation of Tianjin City (15JCZDJC65600) and National Science Foundation of China (31671352) and funding from the National Thousand Young Talents Program and Nankai University.

\section{References}

[1] M. Mandai, A. Watanabe, Y. Kurimoto et al., "Autologous induced stem-cell-derived retinal cells for macular degeneration," The New England Journal of Medicine, vol. 376, no. 11, pp. 1038-1046, 2017.

[2] A. Necsulea, M. Soumillon, M. Warnefors et al., "The evolution of lncRNA repertoires and expression patterns in tetrapods," Nature, vol. 505, no. 7485, pp. 635-640, 2014.

[3] A. Kapusta, Z. Kronenberg, V. J. Lynch et al., “Transposable elements are major contributors to the origin, diversification, and regulation of vertebrate long noncoding RNAs," PLoS Genetics, vol. 9, no. 4, article e1003470, 2013.

[4] P. Bertone, V. Stolc, T. E. Royce et al., "Global identification of human transcribed sequences with genome tiling arrays," Science, vol. 306, no. 5705, pp. 2242-2246, 2004.

[5] P. Kapranov, S. E. Cawley, J. Drenkow et al., "Large-scale transcriptional activity in chromosomes 21 and 22," Science, vol. 296, no. 5569, pp. 916-919, 2002.

[6] P. Kapranov, J. Cheng, S. Dike et al., "RNA maps reveal new RNA classes and a possible function for pervasive transcription," Science, vol. 316, no. 5830, pp. 1484-1488, 2007.

[7] P. Carninci, T. Kasukawa, S. Katayama et al., "The transcriptional landscape of the mammalian genome," Science, vol. 309, no. 5740, pp. 1559-1563, 2005.

[8] E. Birney, J. A. Stamatoyannopoulos, A. Dutta et al., "Identification and analysis of functional elements in $1 \%$ of the human genome by the ENCODE pilot project," Nature, vol. 447, no. 7146, pp. 799-816, 2007.

[9] C. Liu, B. Bai, G. Skogerbø et al., "NONCODE: an integrated knowledge database of non-coding RNAs," Nucleic Acids Research, vol. 33, Database issue, pp. D112-D115, 2005.

[10] C. C. Hon, J. A. Ramilowski, J. Harshbarger et al., "An atlas of human long non-coding RNAs with accurate $5^{\prime}$ ends," Nature, vol. 543, no. 7644, pp. 199-204, 2017.

[11] G. Bussotti, T. Leonardi, M. B. Clark et al., "Improved definition of the mouse transcriptome via targeted RNA sequencing," Genome Research, vol. 26, no. 5, pp. 705-716, 2016.

[12] G. Liang, J. C. Y. Lin, V. Wei et al., "Distinct localization of histone $\mathrm{H} 3$ acetylation and $\mathrm{H} 3-\mathrm{K} 4$ methylation to the transcription start sites in the human genome," Proceedings of the National Academy of Sciences of the United States of America, vol. 101, no. 19, pp. 7357-7362, 2004.

[13] M. G. Guenther, S. S. Levine, L. A. Boyer, R. Jaenisch, and R. A. Young, "A chromatin landmark and transcription initiation at most promoters in human cells," Cell, vol. 130, no. 1, pp. 77-88, 2007.

[14] T. S. Mikkelsen, M. Ku, D. B. Jaffe et al., "Genome-wide maps of chromatin state in pluripotent and lineage-committed cells," Nature, vol. 448, no. 7153, pp. 553-560, 2007.

[15] M. Guttman, I. Amit, M. Garber et al., "Chromatin signature reveals over a thousand highly conserved large non-coding RNAs in mammals," Nature, vol. 458, no. 7235, pp. 223227, 2009.

[16] C. Zhong, Q. Yin, Z. Xie et al., "CRISPR-Cas9-mediated genetic screening in mice with haploid embryonic stem cells carrying a guide RNA library," Cell Stem Cell, vol. 17, no. 2, pp. 221-232, 2015.

[17] X. Lu, F. Sachs, L. A. Ramsay et al., "The retrovirus HERVH is a long noncoding RNA required for human embryonic stem cell identity," Nature Structural \& Molecular Biology, vol. 21, no. 4, pp. 423-425, 2014.

[18] V. Tripathi, J. D. Ellis, Z. Shen et al., "The nuclear-retained noncoding RNA MALAT1 regulates alternative splicing by modulating SR splicing factor phosphorylation," Molecular Cell, vol. 39, no. 6, pp. 925-938, 2010.

[19] J. H. Yoon, K. Abdelmohsen, S. Srikantan et al., "LincRNAp21 suppresses target mRNA translation," Molecular Cell, vol. 47, no. 4, pp. 648-655, 2012.

[20] T. P. Zwaka and J. A. Thomson, "Homologous recombination in human embryonic stem cells," Nature Biotechnology, vol. 21, no. 3, pp. 319-321, 2003. 
[21] A. Giudice and A. Trounson, "Genetic modification of human embryonic stem cells for derivation of target cells," Cell Stem Cell, vol. 2, no. 5, pp. 422-433, 2008.

[22] D. Hockemeyer and R. Jaenisch, "Induced pluripotent stem cells meet genome editing," Cell Stem Cell, vol. 18, no. 5, pp. 573-586, 2016.

[23] A. Hotta and S. Yamanaka, "From genomics to gene therapy: induced pluripotent stem cells meet genome editing," Annual Review of Genetics, vol. 49, no. 1, pp. 47-70, 2015.

[24] S. Alwin, M. B. Gere, E. Guhl et al., "Custom zinc-finger nucleases for use in human cells," Molecular Therapy, vol. 12, no. 4, pp. 610-617, 2005.

[25] J. C. Miller, S. Tan, G. Qiao et al., "A TALE nuclease architecture for efficient genome editing," Nature Biotechnology, vol. 29, no. 2, pp. 143-148, 2011.

[26] F. Zhang, L. Cong, S. Lodato, S. Kosuri, G. M. Church, and P. Arlotta, "Efficient construction of sequence-specific TAL effectors for modulating mammalian transcription," Nature Biotechnology, vol. 29, no. 2, pp. 149-153, 2011.

[27] M. Jinek, K. Chylinski, I. Fonfara, M. Hauer, J. A. Doudna, and E. Charpentier, "A programmable dual-RNA-guided DNA endonuclease in adaptive bacterial immunity," Science, vol. 337, no. 6096, pp. 816-821, 2012.

[28] L. Cong, F. A. Ran, D. Cox et al., "Multiplex genome engineering using CRISPR/Cas systems," Science, vol. 339, no. 6121, pp. 819-823, 2013.

[29] P. P. Amaral, M. B. Clark, D. K. Gascoigne, M. E. Dinger, and J. S. Mattick, "lncRNAdb: a reference database for long noncoding RNAs," Nucleic Acids Research, vol. 39, Supplement 1, pp. D146-D151, 2011.

[30] D. Bhartiya, K. Pal, S. Ghosh et al., "IncRNome: a comprehensive knowledgebase of human long noncoding RNAs," Database, vol. 2013, article bat034, 2013.

[31] C. Park, N. Yu, I. Choi, W. Kim, and S. Lee, "IncRNAtor: a comprehensive resource for functional investigation of long non-coding RNAs," Bioinformatics, vol. 30, no. 17, pp. 2480-2485, 2014.

[32] L. Ma, A. Li, D. Zou et al., "LncRNAWiki: harnessing community knowledge in collaborative curation of human long non-coding RNAs," Nucleic Acids Research, vol. 43, no. D1, pp. D187-D192, 2015.

[33] P. J. Volders, K. Helsens, X. Wang et al., "LNCipedia: a database for annotated human lncRNA transcript sequences and structures," Nucleic Acids Research, vol. 41, no. D1, pp. D246-D251, 2013.

[34] K. Liu, Z. Yan, Y. Li, and Z. Sun, "Linc2GO: a human LincRNA function annotation resource based on ceRNA hypothesis," Bioinformatics, vol. 29, no. 17, pp. 2221-2222, 2013.

[35] J. H. Li, S. Liu, H. Zhou, L. H. Qu, and J. H. Yang, "starBase v2.0: decoding miRNA-ceRNA, miRNA-ncRNA and protein-RNA interaction networks from large-scale CLIP-Seq data," Nucleic Acids Research, vol. 42, no. D1, pp. D92-D97, 2014.

[36] J. Yuan, W. Wu, C. Xie, G. Zhao, Y. Zhao, and R. Chen, "NPInter v2.0: an updated database of ncRNA interactions," Nucleic Acids Research, vol. 42, no. D1, pp. D104-D108, 2014.

[37] P. Wang, S. Ning, Y. Zhang et al., "Identification of lncRNAassociated competing triplets reveals global patterns and prognostic markers for cancer," Nucleic Acids Research, vol. 43 , no. 7, pp. 3478-3489, 2015.
[38] J. H. Yang, J. H. Li, S. Jiang, H. Zhou, and L. H. Qu, "ChIPBase: a database for decoding the transcriptional regulation of long non-coding RNA and microRNA genes from ChIPSeq data," Nucleic Acids Research, vol. 41, no. D1, pp. D177-D187, 2013.

[39] S. Ning, Z. Zhao, J. Ye et al., "SNP@lincTFBS: an integrated database of polymorphisms in human LincRNA transcription factor binding sites," PLoS One, vol. 9, no. 7, article e103851, 2014.

[40] Q. Jiang, J. Wang, Y. Wang, R. Ma, X. Wu, and Y. Li, "TF2LncRNA: identifying common transcription factors for a list of lncRNA genes from ChIP-Seq data," BioMed Research International, vol. 2014, Article ID 317642, 5 pages, 2014.

[41] Z. Zhou, Y. Shen, M. R. Khan, and A. Li, "LncReg: a reference resource for lncRNA-associated regulatory networks," Database, vol. 2015, article bav083, 2015.

[42] Z. Zhao, J. Bai, A. Wu et al., "Co-LncRNA: investigating the lncRNA combinatorial effects in GO annotations and KEGG pathways based on human RNA-Seq data," Database, vol. 2015, article bav082, 2015.

[43] T. Weirick, D. John, S. Dimmeler, and S. Uchida, "C-It-Loci: a knowledge database for tissue-enriched loci," Bioinformatics, vol. 31, no. 21, pp. 3537-3543, 2015.

[44] G. Chen, Z. Wang, D. Wang et al., "LncRNADisease: a database for long-non-coding RNA-associated diseases," Nucleic Acids Research, vol. 41, no. D1, pp. D983-D986, 2013.

[45] Y. Liu and M. Zhao, "InCaNet: pan-cancer co-expression network for human lncRNA and cancer genes," Bioinformatics, vol. 32, no. 10, pp. 1595-1597, 2016.

[46] S. Ning, J. Zhang, P. Wang et al., "Lnc2Cancer: a manually curated database of experimentally supported lncRNAs associated with various human cancers," Nucleic Acids Research, vol. 44, no. D1, pp. D980-D985, 2016.

[47] K. L. Yap, S. Li, A. M. Muñoz-Cabello et al., "Molecular interplay of the noncoding RNA ANRIL and methylated histone $\mathrm{H} 3$ lysine 27 by polycomb CBX7 in transcriptional silencing of INK4a," Molecular Cell, vol. 38, no. 5, pp. 662-674, 2010.

[48] J. L. Rinn, M. Kertesz, J. K. Wang et al., "Functional demarcation of active and silent chromatin domains in human HOX loci by noncoding RNAs," Cell, vol. 129, no. 7, pp. 13111323, 2007.

[49] S. L. Bumgarner, G. Neuert, B. F. Voight et al., "Single-cell analysis reveals that noncoding RNAs contribute to clonal heterogeneity by modulating transcription factor recruitment," Molecular Cell, vol. 45, no. 4, pp. 470-482, 2012.

[50] N. Lin, K. Y. Chang, Z. Li et al., "An evolutionarily conserved long noncoding RNA TUNA controls pluripotency and neural lineage commitment," Molecular Cell, vol. 53, no. 6, pp. 1005-1019, 2014.

[51] K. C. Wang, Y. W. Yang, B. Liu et al., "A long noncoding RNA maintains active chromatin to coordinate homeotic gene expression," Nature, vol. 472, no. 7341, pp. 120-124, 2011.

[52] S. J. Hainer, J. A. Pruneski, R. D. Mitchell, R. M. Monteverde, and J. A. Martens, "Intergenic transcription causes repression by directing nucleosome assembly," Genes \& Development, vol. 25, no. 1, pp. 29-40, 2011.

[53] K. Hirota, T. Miyoshi, K. Kugou, C. S. Hoffman, T. Shibata, and K. Ohta, "Stepwise chromatin remodelling by a cascade 
of transcription initiation of non-coding RNAs," Nature, vol. 456, no. 7218, pp. 130-134, 2008.

[54] D. S. W. Tan, F. T. Chong, H. S. Leong et al., "Long noncoding RNA EGFR-AS1 mediates epidermal growth factor receptor addiction and modulates treatment response in squamous cell carcinoma," Nature Medicine, vol. 23, no. 10, pp. 1167-1175, 2017.

[55] S. Loewer, M. N. Cabili, M. Guttman et al., "Large intergenic non-coding RNA-RoR modulates reprogramming of human induced pluripotent stem cells," Nature Genetics, vol. 42, no. 12, pp. 1113-1117, 2010.

[56] X. Liu, D. Li, W. Zhang, M. Guo, and Q. Zhan, "Long noncoding RNA gadd7 interacts with TDP-43 and regulates Cdk6 mRNA decay," The EMBO Journal, vol. 31, no. 23, pp. 4415-4427, 2012.

[57] L. Zhang, Z. Yang, J. Trottier, O. Barbier, and L. Wang, "Long noncoding RNA MEG3 induces cholestatic liver injury by interaction with PTBP1 to facilitate shp mRNA decay," Hepatology, vol. 65, no. 2, pp. 604-615, 2017.

[58] C. Carrieri, L. Cimatti, M. Biagioli et al., "Long non-coding antisense RNA controls Uchl1 translation through an embedded SINEB2 repeat," Nature, vol. 491, no. 7424, pp. 454-457, 2012.

[59] J. Durruthy-Durruthy, V. Sebastiano, M. Wossidlo et al., "The primate-specific noncoding RNA HPAT5 regulates pluripotency during human preimplantation development and nuclear reprogramming," Nature Genetics, vol. 48, no. 1, pp. 44-52, 2016.

[60] Y. Wang, F. Chen, M. Zhao et al., “The long noncoding RNA HULC promotes liver cancer by increasing the expression of the HMGA2 oncogene via sequestration of the microRNA186," The Journal of Biological Chemistry, vol. 292, no. 37, pp. 15395-15407, 2017.

[61] A. Matsumoto, A. Pasut, M. Matsumoto et al., "mTORC1 and muscle regeneration are regulated by the LINC00961encoded SPAR polypeptide," Nature, vol. 541, no. 7636, pp. 228-232, 2017.

[62] M. Eissmann, T. Gutschner, M. Hämmerle et al., "Loss of the abundant nuclear non-coding RNA MALAT1 is compatible with life and development," RNA Biology, vol. 9, no. 8, pp. 1076-1087, 2012.

[63] Y. Yin, P. Yan, J. Lu et al., "Opposing roles for the lncRNA Haunt and its genomic locus in regulating HOXA gene activation during embryonic stem cell differentiation," Cell Stem Cell, vol. 16, no. 5, pp. 504-516, 2015.

[64] M. R. Capecchi, "Gene targeting in mice: functional analysis of the mammalian genome for the twenty-first century," Nature Reviews Genetics, vol. 6, no. 6, pp. 507512, 2005.

[65] P. A. Latos, S. H. Stricker, L. Steenpass et al., "An in vitro ES cell imprinting model shows that imprinted expression of the $\operatorname{Igf} 2 r$ gene arises from an allele-specific expression bias," Development, vol. 136, no. 3, pp. 437-448, 2009.

[66] P. A. Leighton, R. S. Ingram, J. Eggenschwiler, A. Efstratiadis, and S. M. Tilghman, "Disruption of imprinting caused by deletion of the H19 gene region in mice," Nature, vol. 375, no. 6526, pp. 34-39, 1995.

[67] M. Blasco, W. Funk, B. Villeponteau, and C. Greider, "Functional characterization and developmental regulation of mouse telomerase RNA," Science, vol. 269, no. 5228, pp. 1267-1270, 1995.
[68] J. Feng, W. Funk, S. Wang et al., "The RNA component of human telomerase," Science, vol. 269, no. 5228, pp. 12361241, 1995.

[69] H. Niida, T. Matsumoto, H. Satoh et al., "Severe growth defect in mouse cells lacking the telomerase RNA component," Nature Genetics, vol. 19, no. 2, pp. 203-206, 1998.

[70] J. Huang, F. Wang, M. Okuka et al., "Association of telomere length with authentic pluripotency of ES/iPS cells," Cell Research, vol. 21, no. 5, pp. 779-792, 2011.

[71] E. Herrera, E. Samper, J. Martín-Caballero, J. M. Flores, H. W. Lee, and M. A. Blasco, "Disease states associated with telomerase deficiency appear earlier in mice with short telomeres," The EMBO Journal, vol. 18, no. 11, pp. 2950-2960, 1999.

[72] Y. Liu, D. Luo, H. Zhao, Z. Zhu, W. Hu, and C. H. K. Cheng, "Inheritable and precise large genomic deletions of noncoding RNA genes in zebrafish using TALENs," PLoS One, vol. 8, no. 10, article e76387, 2013.

[73] T. T. Ho, N. Zhou, J. Huang et al., "Targeting non-coding RNAs with the CRISPR/Cas9 system in human cell lines," Nucleic Acids Research, vol. 43, no. 3, article e17, 2015.

[74] M. Zhang, Y. Liu, G. Liu et al., "Rapidly generating knockout mice from H19-Igf2 engineered androgenetic haploid embryonic stem cells," Cell Discovery, vol. 1, article 15031, 2015.

[75] C. Zhong, Z. Xie, Q. Yin et al., "Parthenogenetic haploid embryonic stem cells efficiently support mouse generation by oocyte injection," Cell Research, vol. 26, no. 1, pp. 131$134,2016$.

[76] A. Minkovsky, S. Patel, and K. Plath, "Concise review: pluripotency and the transcriptional inactivation of the female mammalian X chromosome," Stem Cells, vol. 30, no. 1, pp. 48-54, 2012.

[77] A. Wutz, "Xist function: bridging chromatin and stem cells," Trends in Genetics, vol. 23, no. 9, pp. 457-464, 2007.

[78] G. D. Penny, G. F. Kay, S. A. Sheardown, S. Rastan, and N. Brockdorff, "Requirement for Xist in X chromosome inactivation," Nature, vol. 379, no. 6561, pp. 131-137, 1996.

[79] Y. Marahrens, B. Panning, J. Dausman, W. Strauss, and R. Jaenisch, "Xist-deficient mice are defective in dosage compensation but not spermatogenesis," Genes \& Development, vol. 11, no. 2, pp. 156-166, 1997.

[80] F. Mohammad, T. Mondal, N. Guseva, G. K. Pandey, and C. Kanduri, "Kcnq1ot1 noncoding RNA mediates transcriptional gene silencing by interacting with Dnmt1," Development, vol. 137, no. 15, pp. 2493-2499, 2010.

[81] F. Mohammad, R. R. Pandey, T. Nagano et al., "Kcnq1ot1/ Lit1 noncoding RNA mediates transcriptional silencing by targeting to the perinucleolar region," Molecular and Cellular Biology, vol. 28, no. 11, pp. 3713-3728, 2008.

[82] H. J. Lee, J. Kweon, E. Kim, S. Kim, and J. S. Kim, “Targeted chromosomal duplications and inversions in the human genome using zinc finger nucleases," Genome Research, vol. 22, no. 3, pp. 539-548, 2012.

[83] A. Gupta, V. L. Hall, F. O. Kok et al., "Targeted chromosomal deletions and inversions in zebrafish," Genome Research, vol. 23, no. 6, pp. 1008-1017, 2013.

[84] Y. Kim, J. Kweon, A. Kim et al., "A library of TAL effector nucleases spanning the human genome," Nature Biotechnology, vol. 31, no. 3, pp. 251-258, 2013.

[85] P. Essletzbichler, T. Konopka, F. Santoro et al., "Megabasescale deletion using CRISPR/Cas9 to generate a fully haploid 
human cell line," Genome Research, vol. 24, no. 12, pp. 20592065, 2014

[86] J. Han, J. Zhang, L. Chen et al., "Efficient in vivo deletion of a large imprinted IncRNA by CRISPR/Cas9," RNA Biology, vol. 11, no. 7, pp. 829-835, 2014.

[87] M. Sauvageau, L. A. Goff, S. Lodato et al., "Multiple knockout mouse models reveal lincRNAs are required for life and brain development," eLife, vol. 2, article e01749, 2013.

[88] K. M. V. Lai, G. Gong, A. Atanasio et al., "Diverse phenotypes and specific transcription patterns in twenty mouse lines with ablated LincRNAs," PLoS One, vol. 10, no. 4, article e0125522, 2015.

[89] T. Gutschner, M. Baas, and S. Diederichs, "Noncoding RNA gene silencing through genomic integration of RNA destabilizing elements using zinc finger nucleases," Genome Research, vol. 21, no. 11, pp. 1944-1954, 2011.

[90] P. Grote and B. G. Herrmann, "The long non-coding RNA Fendrr links epigenetic control mechanisms to gene regulatory networks in mammalian embryogenesis," RNA Biology, vol. 10, no. 10, pp. 1579-1585, 2013.

[91] P. Grote, L. Wittler, D. Hendrix et al., "The tissue-specific lncRNA Fendrr is an essential regulator of heart and body wall development in the mouse," Developmental Cell, vol. 24, no. 2, pp. 206-214, 2013.

[92] F. Sleutels, R. Zwart, and D. P. Barlow, "The non-coding Air RNA is required for silencing autosomal imprinted genes," Nature, vol. 415, no. 6873, pp. 810-813, 2002.

[93] F. Santoro, D. Mayer, R. M. Klement et al., "Imprinted Igf $2 r$ silencing depends on continuous Airn lncRNA expression and is not restricted to a developmental window," Development, vol. 140, no. 6, pp. 1184-1195, 2013.

[94] P. A. Latos, F. M. Pauler, M. V. Koerner et al., “Airn transcriptional overlap, but not its lncRNA products, induces imprinted Igf2r silencing," Science, vol. 338, no. 6113, pp. 1469-1472, 2012.

[95] E. Aparicio-Prat, C. Arnan, I. Sala, N. Bosch, R. Guigó, and R. Johnson, "DECKO: single-oligo, dual-CRISPR deletion of genomic elements including long non-coding RNAs," BMC Genomics, vol. 16, no. 1, p. 846, 2015.

[96] T. Kono, Y. Obata, Q. Wu et al., "Birth of parthenogenetic mice that can develop to adulthood," Nature, vol. 428, no. 6985, pp. 860-864, 2004.

[97] M. Kawahara, Q. Wu, N. Takahashi et al., "High-frequency generation of viable mice from engineered bi-maternal embryos," Nature Biotechnology, vol. 25, no. 9, pp. 10451050, 2007.

[98] G. Friedrich and P. Soriano, "Promoter traps in embryonic stem cells: a genetic screen to identify and mutate developmental genes in mice," Genes \& Development, vol. 5, no. 9, pp. 1513-1523, 1991.

[99] B. P. Zambrowicz, A. Imamoto, S. Fiering, L. A. Herzenberg, W. G. Kerr, and P. Soriano, "Disruption of overlapping transcripts in the ROSA $\beta$ geo 26 gene trap strain leads to widespread expression of $\beta$-galactosidase in mouse embryos and hematopoietic cells," Proceedings of the National Academy of Sciences of the United States of America, vol. 94, no. 8, pp. 3789-3794, 1997.

[100] P. Soriano, "Generalized lacZ expression with the ROSA26 Cre reporter strain," Nature Genetics, vol. 21, no. 1, pp. 70-1, 1999.
[101] M. Sadelain, E. P. Papapetrou, and F. D. Bushman, "Safe harbours for the integration of new DNA in the human genome," Nature Reviews Cancer, vol. 12, no. 1, pp. 51-58, 2011.

[102] S. Irion, H. Luche, P. Gadue, H. J. Fehling, M. Kennedy, and G. Keller, "Identification and targeting of the ROSA26 locus in human embryonic stem cells," Nature Biotechnology, vol. 25, no. 12, pp. 1477-1482, 2007.

[103] J. D. Brenton, R. A. Drewell, S. Viville et al., “A silencer element identified in Drosophila is required for imprinting of H19 reporter transgenes in mice," Proceedings of the National Academy of Sciences of the United States of America, vol. 96, no. 16, pp. 9242-9247, 1999.

[104] J. Goke, X. Lu, Y. S. Chan et al., "Dynamic transcription of distinct classes of endogenous retroviral elements marks specific populations of early human embryonic cells," Cell Stem Cell, vol. 16, no. 2, pp. 135-141, 2015.

[105] J. Wang, G. Xie, M. Singh et al., "Primate-specific endogenous retrovirus-driven transcription defines naive-like stem cells," Nature, vol. 516, no. 7531, pp. 405-409, 2014.

[106] S. Zhu, W. Li, J. Liu et al., "Genome-scale deletion screening of human long non-coding RNAs using a paired-guide RNA CRISPR-Cas9 library," Nature Biotechnology, vol. 34, no. 12, pp. 1279-1286, 2016.

[107] L. S. Qi, M. H. Larson, L. A. Gilbert et al., "Repurposing CRISPR as an RNA-guided platform for sequence-specific control of gene expression," Cell, vol. 152, no. 5, pp. 1173$1183,2013$.

[108] L. A. Gilbert, M. A. Horlbeck, B. Adamson et al., "Genomescale CRISPR-mediated control of gene repression and activation,” Cell, vol. 159, no. 3, pp. 647-661, 2014.

[109] M. S. Werner, M. A. Sullivan, R. N. Shah et al., "Chromatinenriched lncRNAs can act as cell-type specific activators of proximal gene transcription," Nature Structural \& Molecular Biology, vol. 24, no. 7, pp. 596-603, 2017.

[110] S. J. Liu, M. A. Horlbeck, S. W. Cho et al., "CRISPRi-based genome-scale identification of functional long noncoding RNA loci in human cells," Science, vol. 355 , no. 6320, article eaah7111, 2017.

[111] X. Chen, M. Rinsma, J. M. Janssen, J. Liu, I. Maggio, and M. A. F. V. Gonçalves, "Probing the impact of chromatin conformation on genome editing tools," Nucleic Acids Research, vol. 44, no. 13, pp. 6482-6492, 2016.

[112] J. Hu, Y. Lei, W. K. Wong et al., "Direct activation of human and mouse Oct4 genes using engineered TALE and Cas9 transcription factors," Nucleic Acids Research, vol. 42, no. 7, pp. 4375-4390, 2014.

[113] H. Wu, L. Yang, and L. L. Chen, "The diversity of long noncoding RNAs and their generation," Trends in Genetics, vol. 33, no. 8, pp. 540-552, 2017.

[114] J. Joung, J. M. Engreitz, S. Konermann et al., “Genome-scale activation screen identifies a lncRNA locus regulating a gene neighbourhood," Nature, vol. 548, no. 7667, pp. 343-346, 2017.

[115] A. M. Khalil, M. Guttman, M. Huarte et al., "Many human large intergenic noncoding RNAs associate with chromatinmodifying complexes and affect gene expression," Proceedings of the National Academy of Sciences of the United States of America, vol. 106, no. 28, pp. 11667-11672, 2009.

[116] M. Guttman, J. Donaghey, B. W. Carey et al., "lincRNAs act in the circuitry controlling pluripotency and differentiation," Nature, vol. 477, no. 7364, pp. 295-300, 2011. 
[117] J. M. Engreitz, J. E. Haines, E. M. Perez et al., "Local regulation of gene expression by lncRNA promoters, transcription and splicing," Nature, vol. 539, no. 7629, pp. 452-455, 2016.

[118] D. M. Shechner, E. Hacisuleyman, S. T. Younger, and J. L. Rinn, "Multiplexable, locus-specific targeting of long RNAs with CRISPR-Display," Nature Methods, vol. 12, no. 7, pp. 664-670, 2015.

[119] M. R. O'Connell, B. L. Oakes, S. H. Sternberg, A. EastSeletsky, M. Kaplan, and J. A. Doudna, "Programmable RNA recognition and cleavage by CRISPR/Cas9," Nature, vol. 516, no. 7530, pp. 263-266, 2014.

[120] D. A. Nelles, M. Y. Fang, M. R. O’Connell et al., "Programmable RNA tracking in live cells with CRISPR/Cas9," Cell, vol. 165, no. 2, pp. 488-496, 2016. 

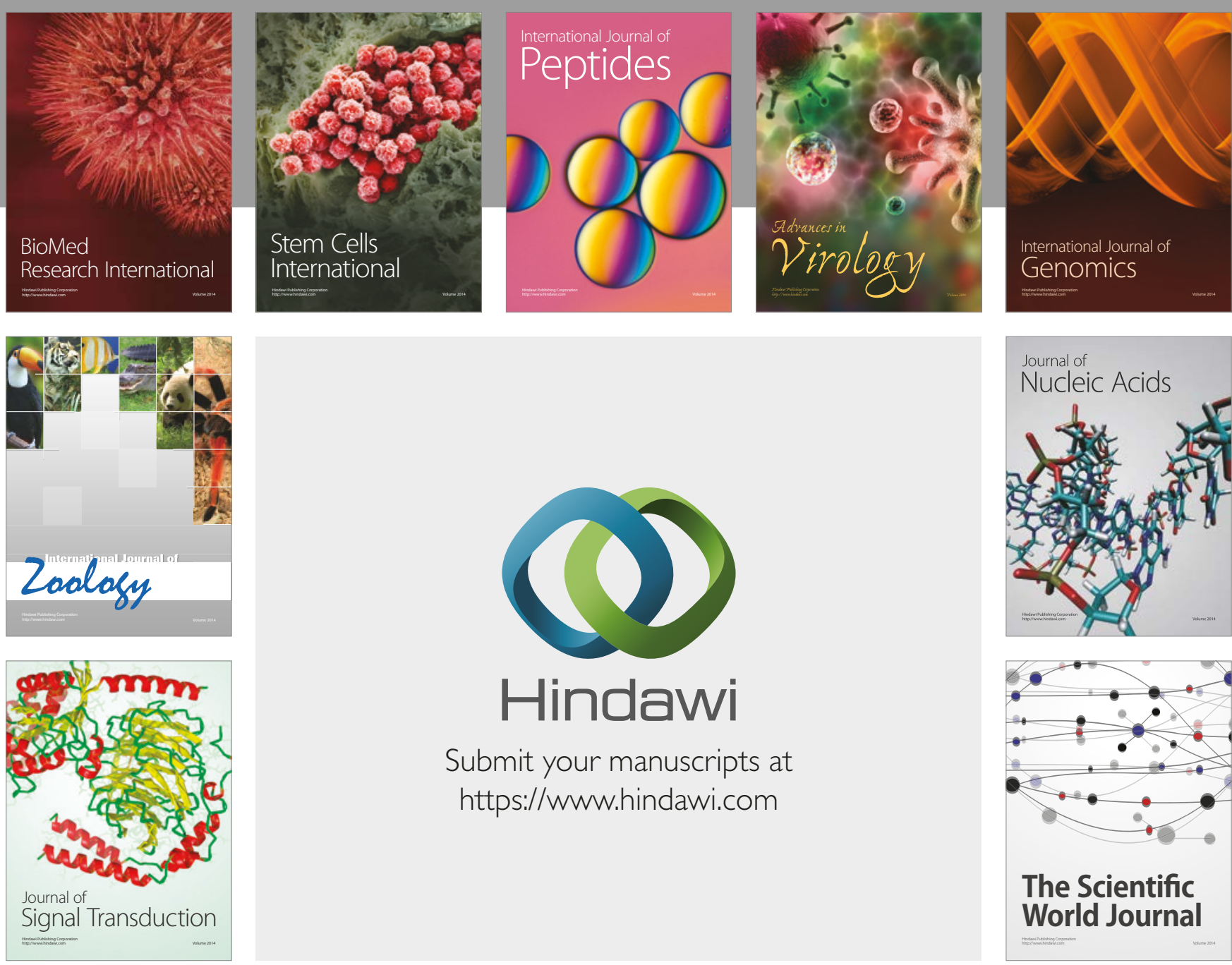

Submit your manuscripts at

https://www.hindawi.com
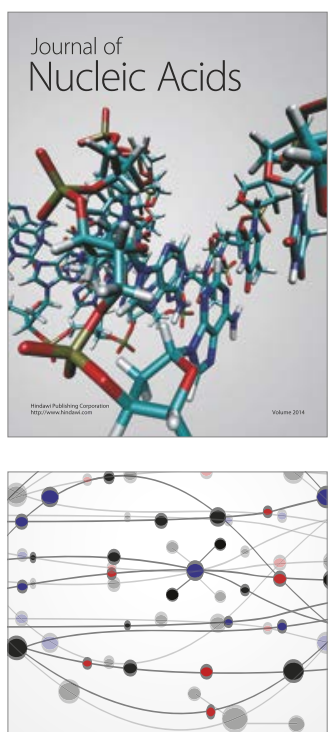

The Scientific World Journal

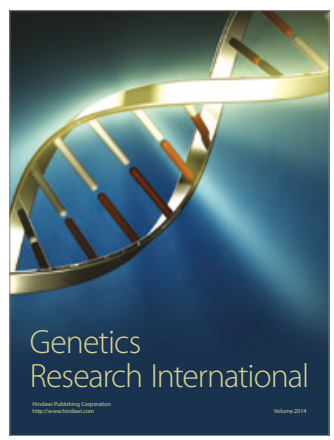

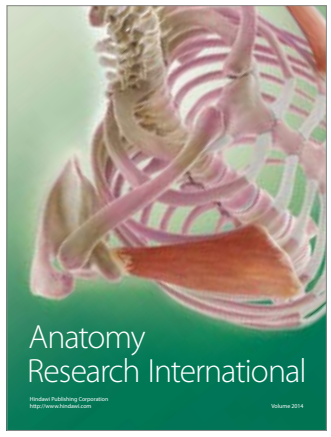

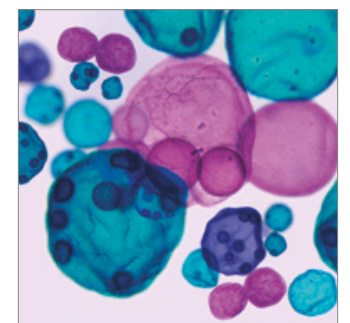

International Journal of Microbiology
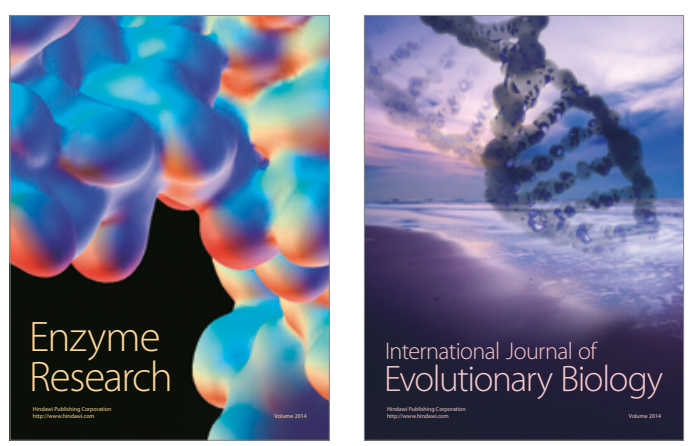
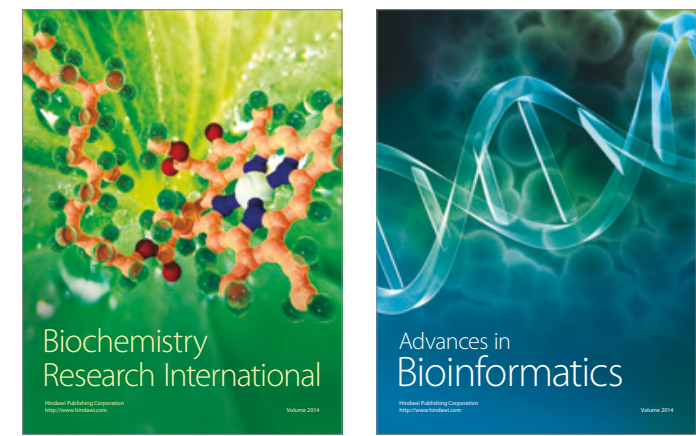

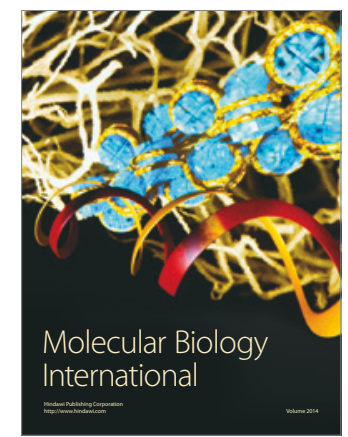

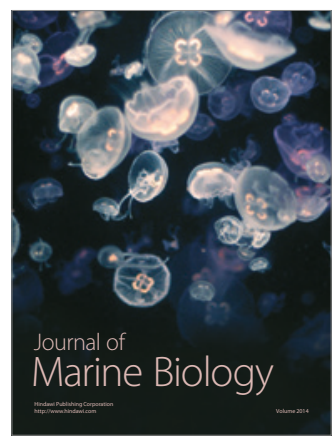

